\title{
Depressed Level Of Consciousness
}

National Cancer Institute

\section{Source}

National Cancer Institute. Depressed Level Of Consciousness. NCI Thesaurus. Code C78253.

A neurologic state characterized by decreased ability to perceive and respond. 